Zbornik Instituta za kriminološka

i sociološka istraživanja

2021 / Vol. XL / 2-3 / 105-122

Pregledni naučni rad

Primljeno: 2. 11. 2021. godine

Prihvaćeno: 22. 11. 2021. godine

DOI: $10.47152 /$ ziksi202123027

UDK: 343.811:616.89-008.441.44

\title{
PREVENCIJA SUICIDALNOSTI OSUĐENIH U ZATVORU
}

\author{
Dragica Bogetić
}

\begin{abstract}
Prepoznavanje, prevencija i intervencija su deo multifaktorskog pristupa redukciji suicidalnosti osuđenih. U skladu sa tim, prvi cilj rada je da se ukaže na značaj mutifaktorskog i multidimenzionalnog modela reagovanja na suicidalnost osuđenih u zatvoru, uvažavajući sledeće segmente: procenu rizika suicidalnosti; nadzor posle prijema $i$ osiguravanje bezbednosti suicidalnog osuđenog; trening zatvorskog osoblja; ključne veštine intervenisanja u slučaju pokušaja suicida; preventivnih aktivnosti od strane drugih osuđenih; multisektorske komunikacije, a u cilju prevencije suicida osuđenih. Drugi cilj rada se odnosi na prikaz CAPRA modela kao predlog alata u obuci zatvorskog osoblja $i$ u rešavanju problema suicidalnosti osuđenih. U radu se koriste analiza $i$ sinteza teorijskih $i$ empirijskih nalaza kroz proučavanje relevantne literature u različitim naučnim izvorima podataka. Od važnosti za prevencïu suicidalnosti osuđenih jeste osvešćivanje zatvorske uprave $i$ osoblja o naučnim saznanjima iz oblasti prevencije i tretmana suicidalnosti osuđenih, a da bi se donela odluka o najdelotvornijoj intervenciji, potrebno je sveobuhvatno $i$ sistematsko znanje o svim faktorima multidimenzionalnog pristupa preventivnom reagovanju.
\end{abstract}

KLJUČNE REČI: suicidalnost / osuđeni u zatvoru / multifaktorska prevencija / CAPRA model

\footnotetext{
${ }^{*}$ Univerzitet u Beogradu - Fakultet za specijalnu edukaciju i rehabilitaciju; saradnik u zvanju asistenta. E-mail: dbogetic992@gmail.com
} 


\author{
Zbormik IKSI, 2-3/2021 - D. Bogetić \\ „Prevencija suicidalnosti osuđenih u zatvoru”, (str. 105-122)
}

\begin{abstract}
UVOD
Suicid osuđenih je važan socijalni problem, imajući u vidu podatke istraživanja prema kojima je stopa suicida u zatvorima znatno viša od stope osoba istog uzrasta i pola iz opšte populacije (Zhong et al., 2021), što osuđene u zatvoru svrstava u jednu od najosetljivijih grupa kada je u pitanju rizik za izvršenje suicida. Ovakva situacija se najčešće objašnjava "izloženošću osetljivih pojedinaca jako stresnim situacijama” (Blaauw et al., 2005).

Studije koje su se bavile suicidalnošću osuđenih u zatvoru potvrđuju da većina poseduje karakteristike koje su indikativne i za izvršenje suicida u opštoj populaciji (Blaauw et al., 2005). Istraživanja u različitim društvima i zatvorskim sistemima ukazuju da oni osuđeni koji su izvršili suicid imaju mnogo zajedničkih karakteristika (Blaauw et al., 2005). Upravo zbog toga, poznavanje i sposobnost procene faktora rizika jesu početni korak prevencije ovog društvenog problema.
\end{abstract}

Uvidom u literaturu o suicidalnosti osuđenih, može se zaključiti da su faktori rizika za suicid u zatvoru, jedna od najčešće empirijski istraživanih tema autora koji se bave ovim fenomenom. Danas, postoji konsenzus u vezi sa faktorima koji mogu doprinositi suicidalnosti, te se najčešće posmatra njihova interakcija u različitim nivoima ekosistema osobe. Etiologija suicida u zatvoru se analizira kroz prizmu sadejstva faktora rizika koji egzistiraju u individualnom domenu (socio-demografski, porodični, psihosocijalni, kriminološki, psihijatrijski) i domenu specifičnosti zatvorskog okruženja (institucionalni faktori rizika). Tradicionalno, na temeljima istraženosti faktora rizika iz ovih domena, koncipiraju se i instrumenti za identifikaciju suicidalnog rizika osuđenih (Kaster et al., 2017), koja predstavlja prvu kariku za dalje delovanje u pravcu prevencije.

Prema ocu savremene suicidologije, Edvinu Šnajdmanu (Edwin Shneidman), suicid je preventabilan društveni problem ukoliko se adekvatno osposobimo za identifikaciju faktora i znakova rizika koji ga mogu pratiti: „Suicid nije bizaran i neshvatljiv čin samodestrukcije. Umesto toga, ljudi koriste određenu logiku, način razmišljanja koji ih dovodi do zaključka da je smrt jedino rešenje njihovih problema. Taj stil i način razmišljanja se može lako videti, i postoje koraci koji se mogu preduzeti kako bi se sprečio suicid, samo ako znamo gde da gledamo" (Shneidman, 1987, str. 58, prema: Hayes, 2013, str. 193).

Prepoznavanje, prevencija i intervencija su deo multidimenzionalnog/ multifaktorskog pristupa redukciji suicidalnosti osuđenih (Kaster et al., 2017). U skladu sa tim, cilj rada je dvojak. Prvi cilj rada je da se ukaže na značaj mutifaktorskog i multidimenzionalnog modela reagovanja na suicidalnost osuđenih u zatvoru, uvažavajući sledeće segmente: procenu rizika suicidalnosti; nadzor posle prijema i osiguravanje bezbednosti suicidalnog osuđenog; trening zatvorskog osoblja u odgovorima na suicidalnost osuđenih; ključne veštine intervenisanja u slučaju pokušaja suicida; značaj preventive nih aktivnosti od strane drugih osuđenih; značaj 


\section{Zbornik IKSI, 2-3/2021 - D. Bogetić \\ „Prevencija suicidalnosti osuđenih u zatvoru”, (str. 105-122)}

multidimenzionalne i multisektorske komunikacije u cilju prevencije suicida osuđenih. Pored toga, drugi cilj rad se odnosi na prikaz CAPRA modela za rešavanje problema kao predlog alata u obuci zatvorskog osoblja i za rešavanje problema suicidalnosti osuđenih. U radu se koriste analiza i sinteza teorijskih i empirijskih nalaza kroz proučavanje relevantne literature $\mathrm{u}$ različitim naučnim izvorima podataka.

\section{MULTIFAKTORSKA PREVENCIJA SUICIDA U ZATVORU}

U zatvorskom okruženju, multifaktorski programi prevencije suicidalnosti osuđenih se smatraju efektivnim programima i podrazumevaju skup različitih modela i tehnika koje bi trebalo primeniti nakon prijema osuđenog u ustanovu (Barker et al., 2014).

Profesor na Univerzitetu u Teksasu (Felthous, 1994) je razvio efektivan preventivni program, koji je sadržao sledeće elemente: identifikaciju - pregled osuđenih, psihološku podršku, dijagnozu i tretman, opažanje i uklanjanje opasnih predmeta, postojanje doslednih smernica u instituciji, i hospitalizaciju u slučaju potrebe. U periodu od 1986. do 1994. godine, u instituciji u kojoj se primenjivao (United States, Galveston, County Jail), nije bilo suicida osuđenih (Barker et al., 2014). Zatim, multifaktorski preventivni program koji je pokazao efektivnost $\mathrm{u}$ smislu redukcije stope suicida u SAD (sa 23,1 na 100.000 između 1984. i 1992. godine, na 12,4 na 100.000 u 1993. godini) u institucijama u kojima se implementirao (Barker et al., 2014), ukazuje na značaj više faktora (Hayes, 1995): obuka zatvorskog osoblja, skrining modela unosa (procena okolnosti i rizičnih karakteristika sa kojima pojedinac dolazi u instituciju), odgovarajući smeštaj i nadzor suicidalnih osuđenih u zavisnosti od procenjenog suicidalnog rizika (opservacija), procedure intervenisanja i nalaze nakon izvršenog samoubistva. Takođe, kontinuirana procena rizika suicidalnosti i kanali komunikacije koji se odvijaju, prvenstveno sa suicidalnim osuđenim, ali i sa drugim važnim informantima, u ovom procesu zahtevaju pažnju (Hayes, 2017).

U skladu sa tim, u nastavku segmenta o preventivnom delovanju na fenomen suicidalnosti u zatvoru, biće operacionalizovani procesi multifaktorskog preventivnog reagovanja.

\section{Procena rizika suicidalnosti}

Prema Svetskoj zdravstvenoj organizaciji, prvi korak u prevenciji suicida jeste procena rizika suicidalnosti osuđenih i razvijanje rizičnog suicidalnog profila (WHO, 2007). Procenu je potrebno izvršiti odmah nakon dolaska osuđenog u zatvor, shodno činjenici da se najveći broj suicida dešava u inicijalnom periodu zatvaranja (Konrad et al., 2007; Slade \& Forrester, 2015; WHO, 2007). Međutim, bez obzira na mnoštvo rizičnih faktora koji su dokazano povezani sa suicidalnošću osuđenih, teško je govoriti o prediktorima takvog ponašanja (Hayes, 2011). Važno je uzeti u obzir i da se rizični profili mogu menjati tokom vremena, te procenu rizika suicidalnosti u 


\section{Zbornik IKSI, 2-3/2O21 - D. Bogetić \\ „Prevencija suicidalnosti osuđenih u zatvoru”, (str. 105-122)}

službi prevencije shvatiti kao permanentan proces (Konrad et al., 2007), koji počinje pri dolasku u zatvor i traje do napuštanja zatvora (Hayes, 2013). Nakon inicijalne identifikacije, potrebno je skrining obaviti i u sledećim situacijama: nakon dobijanja loših vesti, nakon izolacije, nakon što je osuđeni preživeo bilo koji vid poniženja i nakon dugoročnog boravka u zatvorskoj instituciji (Hayes, 2017).

Procena se može izvršiti pomoću instrumenata koji su napravljeni u skladu sa empirijski dokazanim faktorima rizika suicidalnosti osuđenih (Dezsö et al., 2018), a u cilju jasne distinkcije između osuđenih sa suicidalnim rizikom, i onih bez (Blaauw et al., 2001). Ovi instrumenti procenjuju i statičke (istorijske demografske varijable) i dinamičke faktore rizika (porodične, situacione, itd.) (Konrad et al., 2007: 116).

Jedan od instrumenata za procenu suicidalnog rizika, koji je implementiran u pritvorskoj jedinici u Berlinu (Suicide Risk Screening Instrument - SIRAS), uvažava faktore poput godina starosti, prethodnog pritvora, prethodnog pokušaja samoubistva, samopovređivanja, aktuelnih suicidalnih izjava i aktuelnih pokušaja samoubistva (Dezsö et al., 2018). Suicidalni rizik može biti aktivan (kod onih osuđenih kod kojih postoji aktuelan rizik, i za koje se odmah preduzimaju mere opreza) i pasivan (u prošlosti su postojali pokušaji suicida) (Arboleda-Florez \& Holley, 1988).

Znaci da je prisutan pojačan rizik da se izvrši suicid, mogu biti i potvrdni odgovori na sledeće stavke u vezi sa statusom osuđenih (Konrad et al., 2007, str. 116; Hayes, 2011; WHO, 2007):

- Pod dejstvom je psihoaktivnih supstanci ili ima istoriju zloupotrebe psihoaktivnih supstanci.

- Izražava osećanja visokog intenziteta: sramote, krivice i brige zbog trenutne situacije.

- Ispoljava beznadežnost i strah za budućnost, pokazuje znake depresije (plakanje, nedostatak emocija, manjak verbalne ekspresije, teškoće u koncentraciji, promene $u$ apetitu, promene u socijalnom ponašanju). Suicidalnost kod osoba sa depresijom je osam puta češća nego kod onih bez kliničkih znakova depresije (Suicide Prevention Resource Center, 2007; NOMS Agency Board, 2011).

- Ima istoriju tretmana mentalnih poremećaja - 73\% žrtava suicida ima istoriju prihijatrijskog tretmana (Knoll, 2010).

- Pati od psihijatrijskih bolesti - priča „sam sa sobom“, ima teškoće u fokusiranju i/ili audio/vizuelne halucinacije (Suicide Prevention Resource Center, 2007).

- Ima jedan ili više pokušaja suicida ili izražava shvatanje da je suicid prihvatljivo rešenje za izlazak iz problema. Najizraženiji faktor rizika suicida jeste jedan ili više prethodnih pokušaja (Hayes, 2011).

- Izražava postojanje suicidalnog plana - porodici, drugim osuđenima...

- Izražava da ima malo unutrašnjih i spoljnih oslonaca podrške;

- Službenik koji ga je dovezao u zatvorsku jedinicu izražava mišljenje da je osuđeni suicidalan. 


\author{
Zbornik IKSI, 2-3/2021 - D. Bogetić \\ „Prevencija suicidalnosti osuđenih u zatvoru”, (str. 105-122)
}

- Nalazi iz druge ustanove sugerišu da postoji suicidalni rizik.

Pored ovoga, potrebno je obratiti pažnju i na trenutne negativne događaje u životu osuđenih koji mogu pojačati rizik suicida (Suicide Prevention Resource Center, 2007) i na simptome povlačenja iz uobičajenih aktivnosti ili od drugih osuđenih koji mogu biti indikativni (Liebling, 2002).

\title{
Nadzor posle prijema i osiguravanje bezbednosti suicidalnog osuđenog
}

Uočavanje indikatora suicidalnosti osuđenih sadrži nekoliko procesa koje je važno dosledno primeniti (Konrad et al., 2007; SZO, 2000):

- Rutinske provere pomoću kojih se mogu percipirati indikatori: suicidalna namera, simptomi mentalnog stanja - plakanje, nesanica, uznemirenost, tromost, nervozan hod (gore-dole), promene raspoloženja, promene navika u jedenju ili spavanju, gubitak interesovanja za odnose, odbijanje da se uzme lek ili zahtevanje da se pojača doza.

- Razgovor sa osuđenim oko kritičnih emocionalnih perioda (ako se desio gubitak člana porodice, razvod), kako bi se identifikovalo osećanje beznađa ili samoubilačka namera. Ovo je bitno u trenucima kada mogu delovati situacioni okidači poput: dobijanja loše vesti, raskida, nasilja, transfera u drugi zatvor, disciplinske kazne, izolacije u izolovanim sobama (Liebling, 1999).

- Ohrabrivanje porodice da govori o tome da su očili suicidalnu nameru osuđenog, kao i nadzor tokom poseta kako bi se zapazili eventualni problemi i nesuglasice. Dobra saradnja sa porodicom može pomoći u identifikaciji rizika (NOMS Agency Board, 2011).

U zavisnosti od procenjenog nivoa rizika suicidalnosti, sprovodi se intenzitet dalje opservacije i nadzora, te visoko suicidalni osuđeni treba da budu pod konstantnim nadzorom (aktivan suicidalan rizik) (Konrad et al., 2007). Takođe, oni osuđeni kod kojih je procenjen pasivan suicidalni rizik, treba da budu pod nadzorom, ali slabijeg intenziteta (engl. „close observation“) (Hayes, 2017).

Iako svakom slučaju treba prići na individualizovan način, indikatori poput suicidalnih izjava, ozbiljnih i skorašnjih pokušaja suicida, zahtevaju smeštaj pod konstantan nadzor (NOMS Agency Board, 2011). Pojedinci kod kojih je procenjen visoki suicidalni rizik se mogu smestiti u prostorije za intervencije u krizi, u ćelije koje dele sa drugim osuđenima i trebalo bi da se sprovedu specifične opservacije, te da se ulože napori u zaštiti osuđenih od spoljašnjih podražaja (Dezsö et al., 2018). Ćelija koju suicidalni osuđeni deli sa drugim osuđenim licem nije uvek adekvatna opcija, budući da je pristup nebezbednim elementima povećan, a može se desiti i da osuđeni sa kojim deli ćeliju nije prijateljski naklonjen (Konrad et al., 2007). U tom smislu, predlaže se da suicidalni osuđeni budu u ceelijama sa drugima koji bi bili osposobljeni da im pruže socijalnu podršku, i koji bi obavestili zatvorsko osoblje o njihovom uznemirujućem ponašanju (Felthous, 1994). Fizičko izdvajanje suicidalnog osuđenog od ostalih u izolovane ceelije bi trebalo da se radi samo u 
slučajevima kada se ne može primeniti druga strategija, ali se i tada predlaže maksimizacija interakcije osoblja sa osuđenim (Hayes, 2013; NOMS Agency Board, 2011).

Ukoliko se suicidalni osuđeni nalazi u izolovanoj ćeliji, potrebno je osigurati da ne postoje karakteristike fizičke sredine koje pogoduju izvršenju suicida (Suicide Prevention Resource Center, 2007). Npr., potrebno je da ventilacioni otvori nisu izbočeni, da u ćeliji bude krevet sa zaobljenim ivicima i da je osuđeni obučen u odeću koja se ne može iscepati (Hayes, 2013). Dakle, potrebno je da se isključi pristup svim potencijalno letalnim sredstvima (Konrad et al., 2007). Takođe, preporučuje se potpuna vidljivost i preglednost sa spoljašnje strane, izbegavanje kreveta sa bušnim dnom, strujnih utičnica, bilo koje izbočine za koju se može nešto zakačiti (Hayes, 2017). Ponekad je neophodno smestiti osuđenog u ćeliju sa video nadzorom, ali ova intervencija se ne sme poistovetiti sa supervizijom, niti zameniti interakciju osoblja sa osuđenim (NOMS Agency Board, 2011).

Trening zatvorskog osoblja u odgovorima na suicidalnost osuđenih

Krucijalna komponenta dobro osmišljenog programa prevencije jeste trening zatvorskog osoblja (Cutler et al., 1997). Zatvorsko osoblje mora biti obučeno da prepoznaje simptome i moguće reperkusije mentalnih bolesti (Møller et al., 2007). Preduslov dobro osmišljenog programa prevencije suicidalnosti osuđenih jeste da i nemedicinsko zatvorsko osoblje zna da prepozna znakove mentalnih bolesti, beznadežnosti, stava osuđenog koji govori u pravcu „da neće još dugo biti tu“, i da efektivno odgovori na njih (Hayes et al., 2008). Pored toga, osoblje treba biti obučeno za komunikaciju sa osuđenima i drugim osobljem, da razume demografske, situacione i kulturološke faktore rizika, kao i pravila nadzora suicidalnih osuđenih lica (Kennedy \& McKeon, 2004).

Jedan od programa čiji je cilj poboljšanje veština zatvorskog osoblja u proceni i upravljanju rizikom jeste „Program baziran na veštinama upravljanja rizikom“ (Skills-Based Training on Risk Management - STORM) (Hayes et al., 2008). Nalazi pokazuju da ono osoblje koje je prošlo trening veština upravljanja rizikom, ima pozitivnije stavove o programima prevencije suicida osuđenih (National Institute for Health and Care Excellence, 2018). Stoga, kako bi preventivni napori dali željene rezultate, važno je raditi sa osobljem na negativnim stavovima po pitanju sprovođenja prevencije (recimo, otklanjanje stavova poput: „Ako neko stvarno želi da se ubije, ne može se ništa uraditi povodom toga") (Hayes, 2013, str. 193).

Program STORM sadrži četiri modula: procena rizika, upravljanje kriznom situacijom, rešavanje problema i prevencija kriznih situacija. Sadržaj programa se obrađuje na sledeći način: osoblje prolazi kroz učenje o mitovima i činjenicama u vezi sa samoubistvom, prolaze video treninge i vežbaju naučene veštine modelom „igranja uloga“ (Hayes et al., 2008). Trening zatvorskog osoblja je nastao sa ciljem osposobljavanja pružanja neophodne socijalne podrške osuđenima i pokazao se kao obećavajući program (Barker et al., 2014). 


\author{
Zbornik IKSI, 2-3/2021 - D. Bogetić \\ „Prevencija suicidalnosti osuđenih u zatvoru”, (str. 105-122)
}

\title{
Ključne veštine intervenisanja
}

U praktičnom smislu, zatvorsko osoblje treba da bude obučeno za tri ključna koraka intervenisanja u slučaju pokušaja suicida u zatvoru (Hayes, 2011): 1) Za svakog službenika zatvora koji dolazi u rutinski kontakt sa osuđenima je važno da prođe obuku iz prve pomoći - kardiopulmonalne reanimacije, korišćenja opreme za urgentnu pomoć i da se taj trening održava („osvežava“) svake godine (Konrad et al., 2007), jer brzina i osposobljenost službenika za reagovanje ima najvažniju ulogu u spašavanju života. Svaka zatvorska stambena jedinica mora da ima opremu za hitno intervenisanje (Hayes, 2017).

2) Svaki član osoblja treba da proceni i sagleda situaciju kako bi se procenila njena težina, odmah treba da alarmira medicinsko osoblje i ukoliko politika zatvorske ustanove dozvoljava, što pre započne pružanje prve pomoći (Hayes, 2011; Hayes, 2017). Ukoliko je politika ustanove propisala da zatvorski službenik ne sme sam da uđe u ćeliju, potrebno je da se osigura prostor van ćelije, procenjuje situacija i da se pripremi torba sa priborom za spašavanje (komplet za prvu pomoć, maska, štitnik za lice, stabilizator kičme, zavoj za kompresiju odliva krvi, komplet za zaštitu disanja, hirurške rukavice, velike bolničke makaze, džepna maska, defibrilator, alati za ulazak u zatvor i za presecanje užeta) (Suicide Prevention Resource Center, 2007). Potrebno je da se žrtva spusti na pod (koristeći stabilizator kičme ukoliko je žrtva pokušala suicid vešanjem - potrebna je hitna akcija) i da se inicira pružanje prve pomoći kako bi se što pre uspostavilo disanje (Hayes, 2013).

3) Osoblje nikada ne treba da pretpostavlja da je osoba mrtva, već treba da primeni sve mere spašavanja, a medicinsko osoblje je zaduženo da svi alati korisni za spašavanje života budu u provereno funkcionalnom stanju (Hayes, 2011; Hayes, 2017; Suicide Prevention Resource Center, 2007).

Preventivne strategije koje se koriste u zatvorima u velikom segmentu bi trebalo da se fokusiraju na glavne izvore stresa osuđenih, uočavanjem tri ključne oblasti: individualnih vulnerabilnosti osuđenih (poput slabih strategija prevazilaženja, depresivnog stila, naučene bespomoćnosti) kulture zatvorskog osoblja i karakteristika zatvorskog okruženja (Liebling, 1999; Liebling, 2016). Iz ovoga proističe da su glavne preventivne intervencije fokusirane na: tretman i upravljanje psihijatrijskim poremećajima i psihosocijalnim teškoćama osuđenih i promene zatvorskih pravila i okruženja (Marzano et al., 2016). Potrebno je kreirati kulturu zatvora u kojoj se podržavaju i neguju dobri odnosi osuđenih i osoblja (Howells et al., 1999).

U odnosu na psihoterapijske intervencije koje se primenjuju sa osuđenima suicidalnog ponašanja, kognitivno-bihejvioralna terapija je pokazala potencijal $u$ tretmanu (Pratt et al., 2016; Pratt et al., 2015). Pilot randomizirana studija je pokazala da kognitivno-bihevioralna terapija ima efekte u tretiranju psihijatrijskih poremećaja i disfunkcija ličnosti osuđenih, te da je polovina onih koji su prošli ovaj vid terapije pokazala poboljšanje $u$ funkcionisanju u odnosu na četvrtinu onih koji su prošli klasičan vid tretmana (Prat et al., 2015). 


\section{Zbormik IKSI, 2-3/2021 - D. Bogetić \\ „Prevencija suicidalnosti osuđenih u zatvoru”, (str. 105-122)}

U pregledu literature 13 studija, Marcano i saradnici navode, da je jedan od načina prevencije suicida osuđenih ispunjavanje njihove potrebe da budu saslušani, kako od zatvorskog osoblja, tako i od drugih osuđenih (Marzano et al., 2016). Ovaj nalaz može biti u vezi i sa usamljenošću osuđenih, budući da je pronađeno da oni osuđeni koji su postizali više skorove na skalama usamljenosti jesu oni koji su bili depresivniji, imali izraženije osećanje beznadežnosti i pokazivali više indikatora suicidalnog ponašanja (Brown \& Day, 2008).

Primećeno je da su visoko vulnerabilni pojedinci manje izloženi stresu u zatvoru ukoliko postoje određeni sredinski pogodujući faktori, npr. provođenje manje vremena zaključani u ćelijama, kada su zaposleni, kada imaju uredne kontakte sa porodicom (Liebling, 2016), kada pohađaju svrsishodne aktivnosti itd. (Biddle et al., 2018).

Pojedini autori predlažu primenu „Modela životnog puta“ (Seguin et al., 2014) kao jedne od metoda procene rizika suicidalnosti zavorenika, budući da su pronađeni pojedini negativni životni događaji kao faktori rizika suicidalnosti osuđenih i opšte populacije, poput traumatičnih događaja u detinjstvu (emocionalna deprivacija, samopovređivanje, koji sačinjavaju „teret negativnih životnih okolnosti osuđenih“) (Kaster et al., 2017, str. 93).

Takođe, neke od preporuka za segmente adekvatnijeg preventivnog delovanja na suicid u zatvoru, odnose se i na opšte poboljšanje zatvorskih uslova, a pored obuke za podržavajući pristup zatvorskog osoblja, značila bi pomoć od strane specijalizovanog osoblja za one sa traumama („Trauma informed service“) i psihijatrijskim bolestima, kao i bolji pristup lekovima, adekvatnija podrška nakon stresnih okolnosti i sl. (Biddle et al., 2018; Marzano et al., 2012).

\section{Značaj preventivnih aktivnosti od strane drugih osuđenih (engl. „Peer Focused Prevention Activities“)}

Drugi osuđeni mogu imati značajnu ulogu u proceni rizika i prevenciji suicidalnosti (Hall \& Gabor, 2004). Začetak ideje prevencije suicida osuđenih od strane onih sa kojima dele iste trenutne životne okolnosti i sličnost situacije u kojoj se nalaze, počiva na shvatanju da će sposobnost razumevanja biti izraženija upravo kod njih, te da ce i lakše zadobiti poverenje od onih koji su u visokom suicidalnom riziku (Laishes, 1997).

Ovaj program je prvi put primenjen u Kanadi, uključivao je osuđene volontere koji su prošli kombinovanu obuku tematskih lekcija, diskusija i radionice igranja uloga. Obrađene tematske celine su sledeće: koncept prijateljstva, efikasno i aktivno slušanje, neverbalna komunikacija, edukacija o prirodi mentalnih bolesti (npr. šizofrenija, bipolarni poremećaj, depresija), prevencija samoubistva, intervencije u slučaju samoubistva, kao i poznavanje politika i procedure ustanove (Hall \& Gabor, 2004). U skladu sa komentarima zatvorskog osoblja i osuđenih, i niže stope suicida za vreme sprovođenja programa, autori zaključuju da ovakav pristup u preventivnom delovanju ima potencijal u redukciji suicidalnosti osuđenih (Hall \& Gabor, 2004). Slično, pregled programa zasnovanih na dokazima ukazuje na 


\section{Zbornik IKSI, 2-3/2021 - D. Bogetić \\ „Prevencija suicidalnosti osuđenih u zatvoru”, (str. 105-122)}

njegovu obećavajuću ulogu (Barker et al., 2014). Benefiti ovakve koncepcije programa su, u najmanju ruku, dvodimenzionalni, jer osuđeni koji su obučeni za aktivno slušanje i pružanje podrške drugima, razvijaju empatiju, odgovornost, osetljivost na tuđe probleme, doživljaj korisnosti, stvaranje rezilijentnosti (Dhaliwal \& Harrower, 2009).

\section{Značaj multidimenzionalne i multisektorske komunikacije}

Postoje tri faze komunikacije koje su podjednako važne u prevenciji suicidalnosti osuđenih (WHO, 2007):

Komunikacija između policijskih i zatvorskih službenika. Ponašanje osuđenih tokom hapšenja i transporta može biti vrlo indikativno, poput znakova visoke uznemirenosti ili iskazivanja da se nalazi u stanju beznadežnosti. Osoba koja je uhapsila/dovezla osuđenog treba da prenese sve informacije od značaja za situaciju osuđenog zatvorskom osoblju, a saznanjima bi pogodovao i kontakt sa porodicom osuđenog kako bi se dobile relevantne informacije o potencijalnoj suicidalnoj nameri (Hayes, 2011).

Komunikacija među zatvorskim službenicima (zatvorski službenici, zdravstveno osoblje i osoblje za zaštitu mentalnog zdravlja). Multidisciplinarni timski rad je važan segment efektivnosti preventivnog delovanja, te pravovremena i sveobuhvatna razmena informacija između medicinskog i nemedicinskog zatvorskog osoblja, ne sme da izostane (Hayes, 2011; NOMS Agency Board, 2011). O svim znakovima promena u ponašanju (samopovređivanju, suicidalnoj/homicidalnoj ideaciji, poremećajima spavanja i ishrane, neprijateljskom stavu...), stražar treba da obavesti medicinsko osoblje za mentalno zdravlje (Hayes, 1995). Stražar najčešće dolazi prvi u kontakt sa osuđenim koji je pokušao ili izvršio suicid, a osećanja kojima osoblje opisuje svoje stanje nakon tog događaja su često tuga, krivica, nemoć, frustriranost, osećaj neadekvatnosti (Konrad et al., 2007; Liebling, 2002).

Timska podrška koja uključuje razumevanje, utehu i podržavajući pristup za osoblje koje je u kontaktu sa suicidalnim osuđenim, ili pod čijom ingerencijom je osuđeni izvršio suicid, je ključna za prevazilaženje njihovog stresa (Marzano et al., 2012). Takođe, osoblje ima potrebu da oseti da se njihov napor i rad vrednuju od menadžmenta institucije, te ovaj odnos oblikuje i interakciju sa osuđenima i sa drugim kolegama (Møller et al., 2007). Teškoće u timskoj komunikaciji osoblja u zatvorima, ispostavljaju se kao zajednički faktor mnogih suicida (Hayes, 2017).

Komunikacija između zatvorskog osoblja i osuđenih sa suicidalnim ponašanjem

Prema percepciji stražarskog osoblja, nedostatak komunikacije predstavlja važan faktor suicidalnosti osuđenih, pored depresivnosti, prijema loših vesti, osećanja krivice, mentalnih bolesti i zatvorskog pritiska (Liebling, 2002). Pravilna komunikacija između osuđenog i zatvorskog službenika zavređuje posebnu pažnju, jer je sposobnost za aktivno slušanje, empatsku komunikaciju i osećaj kad je 


\section{Zbornik IKSI, 2-3/2O21 - D. Bogetić \\ „Prevencija suicidalnosti osuđenih u zatvoru”, (str. 105-122)}

potrebno da osigura svoje prisustvo pored osuđenog sa suicidalnim rizikom (Hayes, 2011), od važnosti, kako za identifikaciju rizika, tako i u preveniranju neželjenih ishoda. Osuđeni sa suicidalnim rizikom imaju nisko samoupozdanje (Rivlin et al., 2013; Zhong et al., 2019), željni su prepoznavanja i neosuđivanja, poverenja u njihove sposobnosti i mogućnosti da budu saslušani (Liebling, 2002).

Prepoznavanje znakova upozorenja i adekvatno reagovanje na njih je esencijalno i podjednako važno, kako za medicinsko, tako i za nemedicinsko zatvorsko osoblje (Liebling, 2002; Suicide Prevention Resource Center, 2007). Prema određenim procenama, skoro 60\% osuđenih govori o nameri da sebi oduzme život (Daniel, 2006).

Izražavanje suicidalne namere može biti verbalnog „Voleo bih da sam mrtav“ ili „Mojoj porodici bi bilo bolje da mene nema“, ili neverbalnog tipa - u pismima ili drugim putem pisanog izražavanja (Suicide Prevention Resource Center, 2007). Veoma je važno da na ovaj znak upozorenja, zatvorsko osoblje bude obučeno da odgovori na adekvatan način budući da prevencija samopovređivanja i suicidalnosti osuđenih umnogome zavisi od kvaliteta interakcije osoblja i suicidalnog osuđenog (Pannell et al., 2003).

Odluku da se izvrši suicid mogu pojačati stresori iz socijalne sredine, poput konflikata sa osobljem, drugim osuđenima i sa porodicom (Konrad et al., 2007). Važno je znati da nije pogrešno da zatvorski službenik postavi pitanje da li osoba razmišlja o samoubistvu (Konrad et al., 2007), ili da li je žrtva nasilja od strane drugih osuđenih (Liebling, 2002). Potrebno je pristupati pažljivo, ohrabrujuće i sa željom da osuđeni izrazi svoje emocije, čak i ukoliko postoji sumnja da je osuđeni manipulativan (Suicide Prevention Resource Center, 2017).

Postoji set različitih pitanja za koje osoblje treba biti edukovano da postavi u zavisnosti od toga da li se radi o inicijalnoj proceni (npr. „Da li si nekad pomislio da život nije vredan?"), nakon saznanja o suicidalnoj ideaciji (npr. „Šta te je dovelo do takvih misli?"), nakon pokušanog suicida (npr. „Da li možeš da mi opišeš šta se desilo?“) ili nakon ponovljenih suicidalnih ideacija ili pokušaja suicida (npr. „Kada se dogodio tvoj najozbiljniji napad samopovređivanja ili pokušaja suicida?“) (Knoll, 2010).

\section{Ukoliko se pokušaj suicida ili suicid u zatvoru dogodi}

O svakom pokušaju samoubistva ili izvršenom suicidu, svi relevantni zvaničnici treba da budu obavešteni putem izveštaja, kao i porodica žrtve, a svo osoblje koje je imalo kontakt sa žrtvom treba da podnese izjavu uključujući i informacije o poznavanju žrtve (Hayes, 2017).

Ukoliko dođe do suicida, zatvorsko osoblje i zdravstveni radnici imaju sledeće dužnosti (Hayes, 2017; Konrad et al., 2007; SZO, 2000; WHO, 2007): da rekonstruišu događaje koji su doveli do samoubistva; da utvrde činioce koji su doprineli smrti osuđenog (pre suicida su bili zanemareni, ili neodgovarajuce obrađeni); da evaluiraju obuke koje je osoblje prošlo; da procene adekvatnost hitne 
intervencije; da istaknu sve značajne posledice ovog događaja (u službi unapređenja budućih preventivnih postupaka).

Ukoliko postoje adekvatni resursi u instituciji, preporučljivo je da se izvrši i psihološka obdukcija suicida (Hayes, 2017). Psihološka obdukcija suicida ima ulogu u evaluaciji događaja koji su prethodili suicidu, kako bi se kroz propuste koji su uočeni, unele izmene u preventivnim reakcijama.

Kroz ovaj proces se razmatraju sledeći segmenti (Fagan \& White, 2015; National Commission on Correctional Health Care, 2008): faktori koji su doprineli izvršenju suicida, mentalno stanje osuđenih u vreme izvršenja suicida; kroz intervju sa važnim osobama iz okruženja se dobija jasnija slika o okolnostima koji su doprineli suicidu; razmatra se metod izvršenja suicida; obezbeđuje se uočavanje aktuelnog propusta i pruža se mogućnost da se bolje odgovori na potrebe budućih osuđenih sa suicidalnom namerom. Na kraju, identifikuju se nedostaci i propusti u politici sistemskog reagovanja na problem. Ukoliko dođe do neželjenog letalnog ishoda, potrebno je ispraviti brojno stanje osuđenih u instituciji (Hayes, 2017).

\section{CAPRA MODEL ZA REŠAVANJE PROBLEMA}

CAPRA - model koncentričnih krugova za rešavanje problema (eng. acronim: $\mathrm{C}=$ Clients, $\mathrm{A}=$ Acquire/Analyse Information, $\mathrm{P}=$ Partnerships, $\mathrm{R}=$ Response, $\mathrm{A}=$ Assessment of Action), predstavlja deo tzv. „politike orijentisane na problem“ (Scott, 2000). Razvijen je u Kanadi, ranih 9o-ih godina od strane kanadske policije („Royal Canadian Mounted Police“), sa ciljem da se poboljša policijski kontakt sa zajednicom, a nakon toga je počeo uspešno da se koristi kao alat u obuci zatvorskog osoblja za rešavanje problema (Sidebottom \& Tilley, 2011; Thurman \& Jamieson, 2005).

Procesi obuhvaćeni CAPRA modelom su sledeći: identifikovanje postojećih ili potencijalnih problema i povezanih pitanja; održavanje i razvijanje odnosa partnerstva i poverenja među institucijama kako bi se utvrdile prioritetne preventivne oblasti; sticanje i analiziranje relevantnih informacija; razumevanje perspektive klijenta; podsticanje dobijanja povratnih informacija kako bi se evaluiralo urađeno, sagledali propusti i poboljšalo dalje pružanje usluga (United Nations Office on Drugs and Crime, 2013).

Sastavni delovi CAPRA modela mogu biti prikazani u vidu pet koncentričnih krugova u okviru kojih se hronološki posmatrano, nalaze sledeći segmenti:

C (Clients) - Klijenti. Nalaze se u središtu, tj. prvom koncentričnom krugu i odnose se na grupu ili osobu koji mogu biti direktno ili indirektno pogođeni problemom, $\mathrm{u}$ zavisnosti od stepena uključenosti u problem. Direktni klijent je osoba sa kojom zatvorsko osoblje ima direktan kontakt i koja je nosilac problema na koji bi ono trebalo da utiče, a indirektni klijenti su osobe koje bi mogle da utiču na poslove koji se obavljaju u vezi sa datom situacijom (United Nations Office on Drugs and Crime, 2013). U ovom segmentu se određuju potrebe, zahtevi i očekivanja koja ima klijent 


\section{Zbormik IKSI, 2-3/2021 - D. Bogetić \\ „Prevencija suicidalnosti osuđenih u zatvoru”, (str. 105-122)}

sa određenim problemom i što se bolje upoznaju klijentove potrebe i interesi, adekvatnija će biti reakcija na problem (Thurman \& Jamieson, 2005).

Primer za situaciju relevantnu za potencijalno suicidalnog osuđenog:

Zatvorski službenik je primetio da osuđeni M.N. ima ozbiljne povrede po rukama, pokazuje promene $u$ ponašanju, izbegava učestvovanje $u$ svakodnevnim aktivnostima koje je do tada uredno obavljao, nema apetit, a u vreme inicijalnog ispitivanja suicidalnog rizika po dolasku u zatvor, procenjeno je da poseduje pasivni suicidalni rizik. Službenik se priseća da je osuđeni više puta pokušao da započne razgovor sa njim, ali su njegovi pokušaji ostali bezuspešni usled ogromnog obima posla $\mathrm{u}$ instituciji u poslednje vreme. Jedna od potreba osuđenog bi mogla da bude želja za razgovorom i potreba da „bude saslušan“.

Direktni klijent: M.N.

Indirektni klijenti: ostali osuđeni, ostalo disciplinsko i medicinsko osoblje, porodica i prijatelji M.N., društvena zajednica ...;

A (Acquire/Analyse Information) - Sticanje i analiza informacija. U ovom segmentu CAPRA modela se odigrava proces učenja o konkretnom problemu, prikupljaju se podaci iz javnih i privatnih izvora, proučava se istorija konkretnog problema, identifikuju se resursi (UNODC, 2013).

Primer za situaciju relevantnu za potencijalno suicidalnog osuđenog:

Zatvorski službenik uči o faktorima rizika (mentalnim bolestima, traumatičnim događajima, socijalnoj izolaciji itd.) za samopovređivanje i suicidalno ponašanje; izučava potencijalne indikatore (saznaje da promene u ponašanju ili trenutna loša vest, iznenadni gubitak, mogu biti relevantni za problem); konsultuje raniju dokumentaciju osuđenog (da je postojao raniji pokušaj suicida pre transporta $u$ sadašnju instituciju); razmatra koje su njegove ingerencije u datoj situaciji (koga sve treba da obavesti o opaženoj situaciji); konsultuje pravilnike institucije, zakone i druge resurse znanja koji bi doprineli potpunijem razumevanju aktuelne situacije.

P (Partnerships) - Partneri. Mogu biti interni i eksterni, dakle, predstavljaju svaku grupu ili pojedinca u ustanovi ili izvan nje, koji mogu doprineti rešenju problema, recimo stručnjaci iz oblasti problema kojim se bavimo kod direktnog klijenta (psihijatri, specijalni pedagozi, socijalni radnici, naučnici ...) (Thurman \& Jamieson, 2005).

Primer za situaciju relevantnu za potencijalno suicidalnog osuđenog:

Konsultovanje psihijatra u ustanovi ili psihijatra sa iskustvom rada sa suicidalnim osobama van ustanove; Konsultovanje sa ostalim kolegama, kako bi se podelila briga i razmenila iskustva, a drugo osoblje ukoliko je adekvatno obučeno, pružilo podršku; Konsultovanje profesora i doktora nauka iz oblasti suicidologije o potencijalno efektivnim i obećavajućim modelima prevencije i najbezbednijem načinu pristupa; Konsultovanje osoblja koje je bilo u kontaktu sa osuđenim u prethodnoj instituciji, o njihovom mišljenju o tome šta bi konkretnom osuđenom bilo od pomoći; 


\section{Zbormik IKSI, 2-3/2021 - D. Bogetić \\ „Prevencija suicidalnosti osuđenih u zatvoru”, (str. 105-122)}

R (Response) - U procesu odgovora na problem, važno je postupiti u skladu sa prethodnim analizama koje su sprovedene i naći najbolju strategiju, implementirati je i napraviti nacrt za njenu evaluaciju (United Nations Office on Drugs and Crime, 2013).

Primer za situaciju relevantnu za potencijalno suicidalnog osuđenog: Implementiranje tzv. programa aktivnog slušanja od strane drugog osuđenog (eng. „Listener scheme“) i osvežiti obuku iz komunikacije zatvorskog osoblja sa suicidalnim osuđenim licima (Dhaliwal \& Harrower, 2009).

A (Assessment of Action) - Procena. Predstavlja evaluaciju efektivnosti izabranog odgovora, ukazuje na ono što je u odgovoru dobro i na ono što je potrebno modifikovati ili apsolutno promeniti (Thurman \& Jamieson, 2005). Pruža odgovor na pitanje „Da li su postignuti očekivani rezultati?“, u smislu eliminacije ili redukcije problema i u kojoj meri. Pored toga, procenjuju se neželjeni rezultati i određuje se potreba dodatnih resursa (United Nations Office on Drugs and Crime, 2013).

Primer za situaciju relevantnu za potencijalno suicidalnog osuđenog:

Suicidalno ponašanje M.N. se značajno redukovalo, na njegovom telu više nisu vidljivi tragovi povreda, sa znatno većim elanom obavlja svoje dnevne aktivnosti i bioritam mu je uredan. Međutim, osuđeni koji je imao ulogu pružanja neposredne podrške i aktivnog slušanja suicidalnog osuđenog (onaj sa kojim deli ćeliju) počeo je da pokazuje znatno više uznemirenosti, anksioznosti i simptoma sagorevanja. Dakle, može se zaključiti da je multidisciplinarni tim prevideo trenutno psihičko stanje osuđenog koji treba da pruži pomoć suicidalnom, te da je potrebno da ima jasnija uputstva koji su mu resursi dostupni kako bi se stres sa kojim se suočava lakše prevazišao. Jedna od potencijalnih poruka za multidisciplinarni tim: Potrebno je izvršiti i procenu mentalnog stanja osuđenog kome se dodeljuje ova uloga.

\section{ZAKLJUČAK}

Inicijalna procena faktora rizika (što ne osporava značaj procene tokom celog procesa boravka u instituciji) jeste jedan od najvažnijih koraka u prevenciji zatvorskog suicida, ali još važnija je edukacija osoblja o tome kako prepoznati indikatore i kako na njih što pravilnije reagovati. Procena rizika omogućava i da se donese odluka o konkretnoj intervenciji, odnosno omogućava opravdano opredeljenje za konkretnu aktivnost (Knoll, 2010). Dakle, da bi se donela odluka o najdelotvornijoj intervenciji, prethodno je potrebno sveobuhvatno i sistematsko znanje o svim faktorima multidimenzionalnog pristupa preventivnom reagovanju.

Od važnosti za prevenciju suicidalnosti osuđenih jeste osvešćivanje zatvorske uprave i osoblja o naučnim saznanjima iz oblasti prevencije i tretmana suicidalnosti osuđenih. U tom kontekstu, potrebno je spomenuti interesantne analize grupe autora (Gendreau et al., 2009) koji se kritički osvrću na situaciju po pitanju tretmana $u$ popravnim institucijama, uz akcenat na opasnost upotrebe zdravorazumskih intervencija, naročito onih koje su primenjene bez sistematične analize i bez napora da se ne ugrozi valjanost zaključaka. Da bi tretmani bili 


\author{
Zbornik IKSI, 2-3/2O21 - D. Bogetić \\ „Prevencija suicidalnosti osuđenih u zatvoru”, (str. 105-122)
}

dokazano efektivni, trebalo bi, između ostalog, da prođu kroz statistički metod metaanalize, što, prema autorima, nije čest slučaj. Najgori oblik zdravorazumskog rezonovanja (,intuicionizam“, vođen subjektivnim vrednostima i percepcijom problema, često zasnovan na prethodnom individualnom iskustvu) vodi dubokom anti-intelektualizmu. Njime dominiraju nesmotrene generalizacije i princip neupotrebe probabilističkih termina, kauzalnost se smatra nekompleksnim odnosom, a doprinos ozbiljnih empirijskih studija sa eksperimentalnim ili kvazieksperimentalnim nacrtom se zanemaruje. Nauka postoji da bi svojim doprinosom pomogla praksi i pozitivno je promenila, a sve ovo može voditi nečemu što bismo mogli nazvati „nadrilekarstvom, šarlatanstvom“ (Gendreau et al., 2009).

U tom smislu, permanentni napori naučnika i praktičara da svoju profesionalnu viziju obavljaju etično i savesno, uz uzajamno podržavanje i uvažavanje, razmenu iskustava, istraživanje dobrih praksi i pridržavanja njenih pravila, mogu biti od vitalnog značaja za održivost i pozitivne ishode preventivnih programa suicidalnosti osuđenih u zatvoru.

\title{
LITERATURA
}

(1) Arboleda-Florez, J., \& Holley, H. L. (1988). Development of a suicide screening instrument for use in a Remand Centre setting. The Canadian Journal of Psychiatry, 33(7), 595-598. https://doi.org/10.1177/070674378803300704

(2) Barker, E., Kõlves, K., \& De Leo, D. (2014). Management of suicidal and selfharming behaviors in prisons: systematic literature review of evidence-based activities. Archives of Suicide Research, 18(3), 227-240.

https://doi.org/10.1080/13811118.2013.824830

(3) Biddle, P., Dyer, W., Hand, R., \& Strinati, C. (2018). Reflections on a project to prevent suicide and self-harm among prisoners identified as high risk in two prisons in Northern England. Health \& Justice, 6(1), 22. https://doi.org/10.1186/s40352018-0080-7

(4) Blaauw, E., Kerkhof, A. J. F. M., Winkel, F., \& Sheridan, L. (2001). Identifying suicide risk in penal institutions in the Netherlands. The British Journal of Forensic Practice, 3(4), 22-28. https://doi.org/10.1108/14636646200100024

(5) Blaauw, E., Kerkhof, A. J., \& Hayes, L. M. (2005). Demographic, criminal, and psychiatric factors related to inmate suicide. Suicide and Life-Threatening Behavior, 35(1), 63-75. https://doi.org/10.1521/suli.35.1.63.59268

(6) Brown, S., \& Day, A. (2008). The role of loneliness in prison suicide prevention and management. Journal of offender rehabilitation, 47(4), 433-449.

https://doi.org/10.1080/10509670801992459

(7) Cutler, J., Bailey, J., \& Dexter, P. (1997). Suicide awareness training for prison staff: An evaluation. Issues in Criminological \& Legal Psychology, 28, 65-69.

(8) Daniel, A. E. (2006). Preventing suicide in prison: A collaborative responsibility of administrative, custodial, and clinical staff. Journal of the American Academy of Psychiatry and the Law Online, 34(2), 165-175.

(9) Dezsö, D., Konrad, N., Seewald, K., \& Opitz-Welke, A. (2018). Implementation of a suicide risk screening instrument in a remand prison service in Berlin. Frontiers in psychiatry, 9, 665. https://doi.org/10.3389/fpsyt.2018.00665

(10) Dhaliwal, R., \& Harrower, J. (2009). Reducing prisoner vulnerability and providing a means of empowerment: evaluating the impact of a listener scheme on the 


\author{
Zbornik IKSI, 2-3/2O21 - D. Bogetić \\ „Prevencija suicidalnosti osuđenih u zatvoru”, (str. 105-122)
}

listeners. The British Journal of Forensic Practice, 11(3), 35-43.

https://doi.org/10.1108/14636646200900021

(11) Fagan, T., \& White, T. (2015). Psychological autopsy or reconstruction. Dostupno na https://www.ncchc.org/filebin/Resources/Psychological-Autopsy.pdf.

(12) Felthous, A. R. (1994). Preventing jailhouse suicides. Journal of the American Academy of Psychiatry and the Law Online, 22(4), 477-488.

(13) Gendreau, P., Smith, P., \& Theriault, Y. L. (2009). Chaos theory and correctional treatment: Common sense, correctional quackery, and the law of fartcatchers. Journal of Contemporary Criminal Justice, 25(4), 384-396. https://doi.org/10.1177/1043986209344552

(14) Hall, B., \& Gabor, P. (2004). Peer suicide prevention in a prison. Crisis, 25(1), 1926. https://doi.org/10.1027/0227-5910.25.1.19

(15) Hayes, A. J., Shaw, J. J., Lever-Green, G., Parker, D., \& Gask, L. (2008). Improvements to suicide prevention training for prison staff in England and Wales. Suicide and Life-Threatening Behavior, 38(6), 708-713. https://doi.org/10.1521/suli.2008.38.6.708

(16) Hayes, L. (1995). Prison suicide: An overview and a guide to prevention. The prison journal, 75(4), 431-456. https://doi.org/10.1027/0227-5910.16.1.9

(17) Hayes, L. (2011). Guide to developing and revising suicide prevention protocols within juvenile facilities. Baltimore: National Center on Institutions and Alternatives. Dostupno na http://www. ncianet. org/wpcontent/uploads/2015/o5/Guide-to-Developing-an.

(18) Hayes, L. (2013). Suicide prevention in correctional facilities: Reflections and next steps. International journal of law and psychiatry, 36(3-4), 188-194. https://doi.org/10.1016/j.ijlp.2013.04.010

(19) Hayes, L. (2017). Guide to developing and revising suicide prevention protocols within jails and prisons. National Center on Institutions and Alternatives.

(20) Howells, K., Hall, G., \& Day, A. (1999). The management of suicide and selfharm in prisons: Recommendations for good practice. Australian Psychologist, 34(3), 157165. https://doi.org/10.1080/00050069908257449

(21) Kaster, T. S., Martin, M. S., \& Simpson, A. I. (2017). Preventing Prison Suicide with Life Trajectory-Based Screening. The journal of the American Academy of Psychiatry and the Law, 45(1), 92-98.

(22) Kennedy, D. B., \& McKeon, R. (2004). Jail/custody suicide: a compendium of suicide prevention standards and resources. Washington, DC: American Association of Suicidology.

(23) Knoll IV, J. L. (2010). Suicide in correctional settings: Assessment, prevention, and professional liability. Journal of Correctional Health Care, 16(3), 188-204. https://doi.org/10.1177\%2F1078345810366457

(24) Konrad, N., Daigle, M. S., Daniel, A. E., Dear, G. E., Frottier, P., Hayes, L. M., Kerkof, A., Liebling, A., \& Sarchiapone, M. (2007). Preventing suicide in prisons, Part I: Recommendations from the International Association for Suicide Prevention Task Force on Suicide in Prisons. Crisis: The Journal of Crisis Intervention and Suicide Prevention, 28(3), 113. https://doi.org/10.1027/0227-5910.28.3.113

(25) Laishes, J. (1997). Inmate suicides in the Correctional Service of Canada. Crisis: The Journal of Crisis Intervention and Suicide Prevention, 18(4), 157-162. https://doi.org/10.1027/0227-5910.18.4.157

(26) Liebling, A. (1999). Prison suicide and prisoner coping. Crime and Justice, 26, 283359. https://doi.org/10.1086/449299 


\author{
Zbornik IKSI, 2-3/2O21 - D. Bogetić \\ „Prevencija suicidalnosti osuđenih u zatvoru”, (str. 105-122)
}

(27) Liebling, A. (2016). Prison suicide and its prevention. In. Jewkes, Y., Crewe, B., \& Bennett, J. (Eds.). Handbook on prisons. Routledge. https://doi.org/10.4324/9781315797779

(28) Marzano, L., Ciclitira, K., \& Adler, J. (2012). The impact of prison staff responses on selfharming behaviours: Prisoners' perspectives. British journal of clinical psychology, 51(1), 4-18. https://doi.org/10.1111/j.2044-8260.2010.02007.x

(29) Marzano, L., Hawton, K., Rivlin, A., Smith, E. N., Piper, M., \& Fazel, S. (2016). Prevention of suicidal behavior in prisons. Crisis, 37(5), 323-334. https://doi.org/10.1027/0227-5910/a000394

(30) Møller, L., Gatherer, A., Jürgens, R., Stöver, H., \& Nikogosian, H. (2007). Health in prisons: a WHO guide to the essentials in prison health. WHO Regional Office Europe. Dostupno na http://www.euro.who.int/__data/assets/pdf_file/ooo9/99018/E90174.pdf

(31) National Commission on Correctional Health Care (2008). Procedure in the Event of an Inmate Death. Dostupno na https://www.ncchc.org/spotlight-on-thestandards-23-3.

(32) National Institute for Health and Care Excellence. (2018). Preventing suicide in community and custodial settings - Evidence reviews for preventing suicides in custodial and detention settings. Public Health Internal Guideline Development team. Dostupno na

https://www.nice.org.uk/guidance/ng105/resources/preventing-suicide-incommunity-and-custodial-settings-pdf-66141539632069.

(33) NOMS Agency Board. (2011). Management of prisoners at risk of harm to self, to others and from others (Safer Custody). Dostupno na https://www.justice.gov.uk/offenders/psis/prison-service-instructions-2011.

(34) Pannell, J., Howells, K., \& Day, A. (2003). Prison officer's beliefs regarding selfharm in prisoners: an empirical investigation. International Journal of Forensic Psychology, 1(1), 103-110.

(35) Pratt, D., Gooding, P., Awenat, Y., Eccles, S., \& Tarrier, N. (2016). Cognitive behavioral suicide prevention for male prisoners: case examples. Cognitive and behavioral practice, 23(4), 485-501. https://doi.org/10.1016/j.cbpra.2015.09.006

(36) Pratt, D., Tarrier, N., Dunn, G., Awenat, Y., Shaw, J., Ulph, F., \& Gooding, P. (2015). Cognitive-behavioural suicide prevention for male prisoners: A pilot randomized controlled trial. Psychological medicine, 45(16), 3441-3451. https://doi.org/10.1017/Soo33291715001348

(37) Rivlin, A., Hawton, K., Marzano, L., \& Fazel, S. (2013). Psychosocial characteristics and social networks of suicidal prisoners: towards a model of suicidal behaviour in detention. PloS one, 8(7), e68944. https://doi.org/10.1371/journal.pone.0068944

(38) Scott, M. S. (2000). Problem-oriented policing: Reflections on the first 20 years (p. 2000). Washington, DC: US Department of Justice, Office of Community Oriented Policing Services. Dostupno na https://www.popcenter.org/sites/default/files/library/reading/pdfs/reflections.pdf

(39) Seguin, M., Beauchamp, G., Robert, M., DiMambro, M., \& Turecki, G. (2014). Developmental model of suicide trajectories. The British Journal of Psychiatry, 205(2), 120-126. https://doi.org/10.1192/bjp.bp.113.139949

(40) Sidebottom, A., \& Tilley, N. (2011). Improving problem-oriented policing: The need for a new model?. Crime Prevention and Community Safety, 13(2), 79-101. https://doi.org/10.1057/cpcs.2010.21

(41) Slade, K., \& Forrester, A. (2015). Shifting the paradigm of prison suicide prevention through enhanced multi-agency integration and cultural change. The Journal of 


\author{
Zbornik IKSI, 2-3/2O21 - D. Bogetić \\ „Prevencija suicidalnosti osuđenih u zatvoru”, (str. 105-122)
}

Forensic Psychiatry \& Psychology, 26(6), 737-758.

https://doi.org/10.1080/14789949.2015.1062997

(42) Suicide Prevention Resource Center. (2007). What Corrections Professionals Can Do to Prevent Suicide. Dostupno na

https://ubhc.rutgers.edu/tlc/docs/suicideAwareness/SPRC/SPRC\%20Corrections \%20Professionals.pdf.

(43) Suicide Prevention Resource Center. (2017). The Role of Adult Correctional Officers in Preventing Suicide. Dostupno na

http://www.sprc.org/sites/default/files/resource-program/CorrectionOfficers.pdf.

(44) Svetska zdravstvena organizacija (SZO). (2000). Prevencija samoubistva: priručnik za službenike zatvora. Beograd: Institut za mentalno zdravlje. Dostupno na https://www.who.int/mental_health/prevention/suicide/resprison_o05_Serbian_ zatvor.pdf

(45) Thurman, Q. \& Jamieson J. (2005). Police Problem Solving. New York: Routlege. https://doi.org/10.4324/9781315721446

(46) World Health Organization (WHO). (2007). Preventing suicide in jails and prisons. Geneva: Department of Mental Health and Substance Abuse, WHO. Dostupno na https://apps.who.int/iris/bitstream/handle/10665/43678/9789241595506_eng.pd $\mathrm{f}$ ?sequence $=1$ \&isAllowed $=\mathrm{y}$

(47) Zhong, S., Zhu, X., Graham, M., Guo, H., Chen, Y., Luo, C., Li, Q., Zhou, J., \& Wang, $X$. (2019). Mental health problems, history of drug use and violent offending are associated with increased suicide risk in imprisoned females. Frontiers in Psychiatry, 10, 395. http://dx.doi.org/10.3389/fpsyt.2019.00395

(48) Zhong, S., Senior, M., Yu, R., Perry, A., Hawton, K., Shaw, J., \& Fazel, S. (2021). Risk factors for suicide in prisons: a systematic review and meta-analysis. The Lancet Public Health, 6(3), e164-e174. https://doi.org/10.1016/S24682667(20)30233-4 


\section{PREVENTION OF SUICIDALITY OF PRISONERS}

Recognition, prevention and intervention are part of a multifactorial approach to reducing the suicide of convicts. Accordingly, the first goal of the paper is to point out the importance of a multifactorial and multidimensional model of responding to the suicide of convicts in prison, taking into account the following segments: suicide risk assessment; post-admission supervision and ensuring the safety of the suicidal convict; training of prison staff; key skills of intervention in case of suicide attempt; preventive activities by other convicts; multisectoral communications, in order to prevent the suicide of convicts. The second goal of the paper refers to the presentation of the CAPRA model as a proposal of tools in the training of prison staff and in solving the problem of suicide of convicts. The paper uses the analysis and synthesis of theoretical and empirical findings through the study of relevant literature in various scientific data sources. Of importance for the prevention of suicide of convicts is the awareness of the prison administration and staff about the scientific knowledge in the field of prevention and treatment of suicide of convicts, and in order to decide on the most effective intervention, comprehensive and systematic knowledge of all factors of multidimensional approach to preventive response is needed.

KEY WORDS: suicidality / convicts in prison / multifactorial prevention / CAPRA model 